\title{
Turizmin Ekonomik Etkileri: Akdeniz Ülkeleri Örneği*
}

\section{Economic Effects of Tourism: A Case of The Mediterranean Countries}

\author{
Öğr. Gör. Dr. Hasan Önder SARIDOĞAN (iD)1
}

\begin{abstract}
$\ddot{O} \mathbf{z}$
Turizm küresel ekonominin en büyük ve en hızlı büyüyen sektörlerinden birisidir. Turizm istihdam, gelir, dış ödemeler dengesi ve bölgesel kalkınma gibi konularda sağladığı katkılarla ülke ekonomilerinde önemli bir yere sahiptir. Sektör ekonomik etkilerinin yanında sosyal ve kültürel etkileri ile de önemli bir yer tutmaktadır. Akdeniz ülkeleri dünyanın en çok turist çeken ve turizm geliri elde eden bölgelerin başında gelmektedir. Turizm geliri ve uluslararası turist sayısı açısından ön sıralarda yer alan bu ülkelerin ekonomik büyümeleri ve kalkınmasında turizm sektörünün payı araştıılması gereken konuların başında gelmektedir. Bu çalışmanın amacı, 1995-2017 döneminde 7 Akdeniz ülkesinin turizm gelirleri, uluslararası turist sayısı ve ekonomik büyüme arasındaki ilişkileri araştırmaktır. Panel veri regresyon modellerinin ele alındığ analizde, tesadüfi etkiler modelinin uygun olduğu görülmüştür. Model, varsayımlardan sapmalara karşı geliştirilen Arellano, Froot ve Rogers dirençli standart tahmincileriyle tahmin edilmiştir. Sonuçlar, 7 Akdeniz ülkesinde turizm ile ekonomik büyüme arasında pozitif bir ilişki olduğunu göstermektedir. Buna göre, uluslararası turist sayısındaki \%1'lik bir artış ekonomik büyümeyi $\% 0,09$ oranında artırıken, turizm gelirlerindeki \%1'lik bir artış ekonomik büyümeyi \%0,07 artırmaktadır.
\end{abstract}

Anahtar Kelimeler: Turizm, ekonomik büyüme, panel analiz

Makale Türü: Araştırma

\begin{abstract}
Tourism is one of the largest and fastest growing sectors of the global economy. With its contributions to employment, income level, foreign payment balance, regional development etc., tourism has an important place within the overall economy of countries. Mediterranean countries are one of the most popular tourist destinations in the world. The share of tourism sector in the economic growth and development of these countries which are at the forefront in terms of tourism income and the number of international tourists is among the issues that need to be investigated. The aim of this study is to examine the relationship between tourism revenues, international tourist arrivals and economic growth, using data from 7 Mediterranean countries 1995-2017. As discussed in the analysis of panel data regression model, the random effects model was found to be suitable. The model developed against deviations from assumptions, has been estimated by Arellano, Froot ve Rogers robust standard estimator. The results indicate that there is a positive relationship between tourism and economic growth in 7 Mediterranean countries. In this context that a $\% 1$ increase in number of international tourists gives way to a $\% 0,09$ increase in economic growth and $\% 1$ increase in tourism revenues gives way to a $\% 0,07$ increase in economic growth.
\end{abstract}

Keywords: Tourism, economic growth, panel analysis

Paper Type: Research

\footnotetext{
${ }^{*}$ Bu çalışmanın ilk hali Antalya'da düzenlenen 5. Uluslararası İnsan, Toplum ve Spor Bilimleri kongresinde sözlü bildiri olarak sunulmuştur.

${ }^{1}$ Akdeniz Üniversitesi, Kumluca MYO, ondersaridogan@akdeniz.edu.tr.

Atıf için (to cite): Sarıdoğan, H. Ö. (2019). Turizmin Ekonomik Etkileri: Akdeniz Ülkeleri Örneği. Afyon Kocatepe Üniversitesi Sosyal Bilimler Dergisi, 21(4), 1308-1315.
} 


\section{Giriş}

Turizm endüstrisi 20 yüzyılın ikinci yarısından itibaren dünya ekonomisi için büyük öneme sahip bir sektör halini almış ve birçok ülke için en önemli iktisadi alanlardan biri olmuştur. Günümüzde turizm faaliyetleri dünya çapında bir ekonomik büyüme kaynağı olarak kabul edilmektedir. Turist harcamaları, ülkelerin döviz ihtiyacının bir kısmını karşılayarak ödemeler dengesine katkıda bulunan alternatif bir ihracat şekline bürünmüştür. Turizmin olumlu etkisi sadece ödemeler dengesinde değil istihdam, gelir ve üretim üzerinde de kendini hissettirmektedir. Böylece turizmin genel ekonomik büyümeyi tetiklediği konusunda genel bir fikir birliği ortaya çıkmıştır. Turizm, çeşitli alt endüstrileri içeren ve çeşitli becerilere dayanan çok disiplinli bir faaliyet olduğundan, faydaları, ekonominin diğer sektörleriyle karşılaştırmalı olarak toplumun daha geniş bir bölümüne yayılmaktadır.

Dünya Turizm Örgütü (2018) raporuna göre, Avrupa bölgesi 672 milyon turist sayısı ve 519 milyar dolar turizm geliri ile dünyanın en önemli turizm merkezidir. Avrupa bölgesi içerisinde yer alan Akdeniz havzası ise en çok turist çeken ve turizm geliri elde eden bölgedir.

Tablo 1'de Akdeniz havzasında en çok turist çeken ve en çok turizm geliri elde eden 7 ülkenin turizm verileri yer almaktadır.

Tablo 1. 2017 yılı 7 Akdeniz ülkesi turizm verileri

\begin{tabular}{lcccc}
\hline \multicolumn{1}{c}{ Ülke } & $\begin{array}{c}\text { Turizm Geliri } \\
\text { (Milyon \$) }\end{array}$ & $\begin{array}{c}\text { Avrupa'da } \\
\text { Payı \% }\end{array}$ & $\begin{array}{c}\text { Uluslararası Turist } \\
\text { Sayısı (1000) }\end{array}$ & $\begin{array}{c}\text { Avrupa'da } \\
\text { Payı \% }\end{array}$ \\
\hline İspanya & 67,964 & 13,1 & 81,786 & 12,2 \\
Fransa & 86,918 & 13 & 60,681 & 11,7 \\
İtalya & 44,233 & 8,5 & 58,253 & 8,7 \\
Türkiye & 22,478 & 4,3 & 37,601 & 5,6 \\
Portekiz & 17,119 & 3,3 & 21,200 & 3,2 \\
Yunanistan & 16,528 & 3,2 & 27,194 & 4,1 \\
Hırvatistan & 10,924 & 2,1 & 15,593 & 2,3 \\
\hline
\end{tabular}

Kaynak: UNWTO Tourism Highlights, 2018 Edition

Tablo 1'e göre, uluslararası turist sayısında ilk sirada İspanya bulunurken, turizm gelirlerinde ise ilk sırada Fransa yer almaktadır. İspanya'da 2017 y1lında 81,7 milyon turiste karşıl1k 67,9 milyar dolar turizm geliri elde edilmiştir. Fransa'da ise aynı yıl 60,6 milyon turiste karşıl1k 86,9 milyar dolar turizm geliri elde edilmiştir. Türkiye Rusya ile yaşadığı uçak krizinin ${ }^{2}$ atlatılmasından sonra 2017 yılında bir önceki yıla göre turist sayısını $\% 24,1$, turizm gelirlerini ise yaklaşık \%20 oranında artırmışır.

Turizm, Akdeniz ülkeleri ekonomisine milyarlarca dolar kaynak sağlayan en önemli sektörlerden birisidir. Bu bağlamda, bu ülkelerdeki turizm sektörünün ekonomik büyümeye katkısının araştırılması önem arz etmektedir.

Bu çalışmada 7 Akdeniz ülkesi İspanya, İtalya, Fransa, Türkiye, Yunanistan, Portekiz ve Hırvatistan'ın 1995-2017 döneminde ait turizm geliri ve turist sayısının ekonomik büyüme üzerindeki etkisi panel veri analizi yöntemi ile araştırılmıştır. Çalışmada öncelikli olarak bu ülkeler ile ilgili yapılan çalışmalara ait literatür özetlenmiştir. Sonrasında ampirik analiz ile ilgili veri seti, model ve ekonometrik yöntem tanıtılarak uygulanan test sonuçları bir sonraki başlıklarda sunulmuştur. Son bölümde ise genel bir değerlendirme yapılarak çalışma sonlandırılmıştır.

\footnotetext{
${ }^{2}$ Türkiye, 24 Kasım 2015 tarihinde Suriye'nin kuzeyinde hava saldırıları düzenleyen bir Rus savaş uçağını hava sahası ihlali gerekçesi ile düşürdükten sonra Rusya ile yaşanan diplomatik kriz.
} 


\section{Literatür}

Turizm ve ekonomik büyüme arasındaki ilişkileri inceleyen çok sayıda ampirik çalışma mevcuttur. Bu çalışmada Akdeniz ülkeleri bazında yapılan araştırmalara yer verilmiştir. Balaguer and Cantavella-Jordá (2002), 1975-1997 döneminde İspanya'da ihracata dayalı bir büyüme yaklaşımı ile turizm sektörünün ekonomik büyümedeki rolünü incelemiştir. Eş bütünleşme ve nedensellik testlerinin kullanıldığı çalışmada İspanya'nın ekonomik büyümesinin uluslararası turizm hareketlerinden etkilendiği tespit edilmiştir. Dritsakis (2004), 1960: I - 2000: IV dönemi için Yunanistan'ın reel GSYH, reel efektif döviz kuru ve uluslararası turizm gelirlerini kullanarak turizm ve büyüme arasındaki ilişkileri incelemiştir. Nedensellik analizi ve VAR modelinin kullanıldığı çalışmada, uzun dönemde uluslararası turizm gelirleri ile ekonomik büyüme arasında güçlü bir Granger nedensellik olduğu tespit edilmiştir. Gündüz ve Hatemi-J (2005), Türkiye'nin 1963-2002 dönemine ait verileri ile turizm ile ekonomik büyüme ilişkisini test etmiştir. Kaldıraçlı (Leveraged) Bootstrap nedensellik testlerinden yararlanılan çalışma sonuçlarına göre, Türkiye'nin turizm öncülüğündeki büyüme hipotezi ampirik olarak desteklenmiştir. Ongan ve Demiröz (2005), uluslararası turizm gelirlerinin Türkiye'nin uzun vadeli ekonomik büyümesi üzerindeki etkilerini ampirik olarak incelemiştir. Çalışmada, turizm kaynaklı büyüme hipotezi eş bütünleşme ve Granger nedensellik testi kullanılarak test edilmiştir. 1980: 1-2004: 2 dönemi için Johansen tekniği kullanılmış ve vektör hata düzeltme modellemesi (VECM) Granger nedensellik testlerine dahil edilmiştir. Analiz sonuçlarına göre, ekonomik büyümenin turizmin sektörel gelişimine katkıda bulunduğu, turizmin de ekonomik büyümeyi pozitif etkilediği tespit edilmiştir. Gökovalı ve Bahar (2005), 1987-2002 döneminde 13 Akdeniz ülkesinin verilerini kullanarak bir panel veri analizi gerçekleştirmiştir. Turizm gelirleri (\%toplam ihracat) ve sabit sermaye miktarı (\%GSYH) ile GSYH'deki büyüme oranının kullanıldığı çalışma sonuçlarına göre, söz konusu ülkelerde, turizmin ekonomik büyümeye katkıda bulunduğu tespit edilmiştir. Proenca ve Soukiazis (2008), 1990-2004 döneminde dört Güney Avrupa ülkesinin verileri ile bir panel veri analizi gerçekleştirmiştir. Analiz sonuçları, turizmin bu ülkelerdeki yaşam standardının gelişimine önemli ölçüde katkıda bulunduğunu ve yakınsama faktörü olarak hareket ettiğini göstermektedir. Dritsakis (2012), 1980-2007 döneminde yedi Akdeniz ülkesinin kişi başına reel turizm geliri, kişi başına uluslararası turist sayısı, reel efektif döviz kuru ve kişi başına reel GSYIH değişkenlerini kullanarak bir dinamik panel analizi uygulamıştır. Yeni heterojen panel eş bütünleşme testleri ve FMOLS modeli uygulanarak gerçekleştirilen çalışma sonuçlarına göre, ele alınan yedi Akdeniz ülkesinde turizm gelişimi ile GSYH arasındaki panel eş bütünleşme ilişkilerine dair sağlam kanıtlar bulunmaktadır. FMLOS tahminleri ise, turizm gelirlerinin GSYH üzerinde daha yüksek bir etkisi olduğunu göstermektedir.

\section{Ampirik Analiz}

\subsection{Veri Seti}

Turizm gelirlerinin ve uluslararası turist sayısının ekonomik büyüme üzerindeki etkisini araştıran bu çalışmanın veri seti 7 Akdeniz $^{3}$ ülkesini kapsamaktadır. Çalışmada 1995-2017 yılına ait veriler panel veri analizi yöntemiyle test edilmiştir. Analizde kullanılan tüm değişkenlerin doğal logaritmaları alınmıştır. Modelde kullanılan değişkenler Tablo 2'de gösterilmektedir.

Tablo 2. Modelde yer alan değişkenler

\begin{tabular}{lll}
\hline & Değişken Tanımı & Kaynak \\
\hline InGDP & GSYH (Sabit 2010 \$) & World Bank \\
\hline $\operatorname{lnK}$ & Sabit Sermaye Birikimi (Sabit 2010 \$) & World Bank \\
\hline $\operatorname{lnL}$ & İsügü Miktarı & World Bank \\
\hline InTNUM & Uluslararası Turist Sayısı & World Bank \\
\hline InTREC & Uluslararası Turizm Gelirleri (\$) & World Bank \\
\hline
\end{tabular}

\footnotetext{
3 İspanya, İtalya, Fransa, Türkiye, Yunanistan, Portekiz, Hırvatistan
} 
Modelde ekonomik büyümenin göstergesi olarak reel GSYH, turizm sektörünü temsilen uluslararası turist sayısı ve uluslararası turizm gelirleri belirlenmiştir. Ayrıca ister firma ister ülke bazında olsun en temel üretim faktörleri emek ve sermayedir. Bu bağlamda emeği temsilen toplam işgücü miktarı ve sermayeyi temsilen sabit sermaye birikimi büyüme modelimize kontrol değişken olarak ilave edilmiş̧ir. Değişkenlere ait özet istatistiklere Tablo 3’te yer verilmiştir.

Tablo 3. Özet istatistikler

\begin{tabular}{lccccc}
\hline & Gözlem Sayısı & Ortalama & Standart Sapma & Minimum & Maksimum \\
\hline InGDP & 161 & 27.02666 & 1.297059 & 24.40076 & 28.68696 \\
$\operatorname{lnK}$ & 161 & 25.49941 & 1.340315 & 22.51771 & 27.24551 \\
$\operatorname{lnL}$ & 161 & 16.19913 & .9863804 & 14.40646 & 17.25834 \\
$\operatorname{lnTNUM}$ & 161 & 16.8986 & .9599312 & 14.21093 & 18.27982 \\
$\operatorname{lnTREC}$ & 161 & 23.67305 & .9105326 & 21.02263 & 24.97025 \\
\hline
\end{tabular}

\subsection{Model ve Yöntem}

1995-2017 döneminde 7 Akdeniz ülkesinde turizmin ekonomik büyüme üzerindeki etkisi aşağıdaki fonksiyonel ilişki yardımıyla incelenmiştir.

$$
\operatorname{lnGDP} P_{i t}=\alpha_{i}+\beta_{1} K_{i t}+\beta_{2} L_{i t}+\beta_{3} T N U M_{i t}+\beta_{4} T R E C_{i t}+u_{i t}
$$

Fonksiyonda yer alan $i$ alt indisi ülkeleri, $t$ alt indisi zamanı, $\beta$ tahmin edilen katsayıyı, $u$ hata terimini göstermektedir. Çalışmada yer alan değişkenler STATA 13.0 bilgisayar paket programı kullanılarak panel veri analizi yöntemiyle test edilmiştir.

Panel veri analizinde klasik model, sabit etkiler modeli ve tesadüfi etkiler modeli olmak üzere üç tür model kullanılmaktadır. Bu modeller arasından hangisinin kullanılacağı çeşitli spesifikasyon testleri ile belirlenmektedir. Çalışmada klasik modeli sabit etkiler modeline karşı sınayan F testi, klasik modeli tesadüfi etkiler modeline karşı sınayan Score testi ve son olarak tesadüfi etkiler modelini sabit etkiler modeline karşı sınamak için Hausman testi kullanılmıştır. Test sonuçlarına göre çalışmada kullanılan fonksiyonel ilişkinin tesadüfi etkiler modeli ile anlamlı sonuçlar verdiği tespit edilmiştir. Sonraki aşamada tesadüfi etkiler modelinin temel varsayımlarından değişen varyans varsayımı için Levene, Brown ve Forsythe (1974) testi, otokorelasyon varsayımı için Bhargava, Franzini ve Narendranathan'nın (1982) Durbin Watson ve Baltagi-Wu testi uygulanmıştır. Tesadüfi etkiler analizinde birimler tesadüfi çekimden geldiği için birimler arası korelasyona rastlanması beklenmemektedir (Tatoğlu, 2016: 233).

\section{Ampirik Bulgular}

Çalışmada kullanılacak panel veri yönteminin belirlenmesinden önce Tablo 4'te havuzlanmış klasik, sabit ve tesadüfi etkiler modellerine ait analiz sonuçlarına yer verilmiştir.

Tablo 4. Klasik, Sabit Etkiler, Tesadüfi Etkiler model sonuçları

\begin{tabular}{|c|c|c|c|c|c|c|}
\hline & \multicolumn{2}{|c|}{ POLS } & \multicolumn{2}{|c|}{ Sabit Etkiler Modeli } & \multicolumn{2}{|c|}{ Tesadüfi Etkiler Modeli } \\
\hline InGDP & Katsayılar & $\begin{array}{c}\text { Standart } \\
\text { Hata }\end{array}$ & Katsayılar & $\begin{array}{c}\text { Standart } \\
\text { Hata }\end{array}$ & Katsayılar & $\begin{array}{c}\text { Standar } \\
\text { Hata }\end{array}$ \\
\hline $\ln K$ & $.7283 * * *$ & .0463 & $.2692 * * *$ & .0101 & $.2739 * * *$ & .0116 \\
\hline $\ln \mathbf{L}$ & $.1948 * * *$ & .0509 & $.6594 * * *$ & .0366 & $.7118 * * *$ & .0318 \\
\hline InTNUM & $.1116 * *$ & .0458 & $.0870 * * *$ & .0144 & $.0949 * * *$ & .0163 \\
\hline InTREC & .0377 & .0473 & $.0827 * * *$ & .0118 & $.0733 * * *$ & .0131 \\
\hline Sabit & 2.518 & .4580 & $6.048 * * *$ & .5065 & $5.168 * * *$ & .4239 \\
\hline $\mathbf{R 2}$ & \multicolumn{2}{|c|}{0.98} & \multicolumn{2}{|c|}{0.96} & \multicolumn{2}{|c|}{0.96} \\
\hline $\mathbf{F}$ & \multicolumn{2}{|c|}{ Prob $>F=0.0000$} & \multicolumn{2}{|c|}{$\begin{array}{l}F(6,150)=932.31 \\
\text { Prob > F }=0.0000\end{array}$} & \multicolumn{2}{|c|}{$\begin{aligned} \text { Wald chi2 } 2(4) & =4738.83 \\
\text { Prob }>\text { chi } 2 & =0.0000\end{aligned}$} \\
\hline
\end{tabular}

*** \%1, **\%5, *\%10 düzeyinde anlamlı test sonuçlarını ifade etmektedir. 


\subsection{F Testi}

F testinde tüm birim etkilerin sıfira eşit olduğu hipotezi $\left(H_{0}: u_{i}=0\right)$ test edilmiştir. (Tatoğlu, 2016: 171). F testi için Tablo 4'ün son sütununda yer alan sabit etkiler modelinin F istatistiğine bakmak yeterli olacaktır. Prob $>F=0.0000$ olduğu için birim etkilerin sıfıra eşit olduğunu ileri süren $H_{0}$ hipotezi reddedilmiştir. Modelde birim etkilerin var olduğu dolayısıyla havuzlanmış klasik modelin uygun olmadığ 1 , sabit etkiler modelinin uygun olduğu sonucuna ulaşılmıştır.

\subsection{Score Testi}

Score testi havuzlanmış klasik modeli tesadüfi etkiler modeline karşı sınamak amacıyla kullanılmaktadır. Söz konusu test, küçük örnek özelliği gösteren analizlerde daha başarılı sonuçlar vermektedir (Tatoğlu, 2016: 181). Score testinde birim etkinin standart hatasının sıfıra eşit olduğunu öne süren $\left(H_{0}: \sigma_{\mu}=0\right)$ hipotezi test edilmektedir. Tablo 5 'te, Prob $>=$ chi2 $=0.000$ olduğu için $H_{0}$ hipotezi reddedilmiştir. Modelde birim etkilerin olduğu dolayısıyla havuzlanmış klasik modelin uygun olmadığı, tesadüfi etkiler modelinin uygun olduğu sonucuna ulaşılmıştır.

Tablo 5. Score Testi sonuç tablosu

\begin{tabular}{ccc}
\hline InGDP & ML Tahmini* & [95\% Güven Aralığ $\mathbf{l}]$ \\
\hline /sigma_u & 0.2271055 & 0.1679556 \\
Score test of sigma_u=0: $\operatorname{chi} 2(1)=5.5 \mathrm{e}+06$ & Prob $>=\mathbf{c h i 2}=\mathbf{0 . 0 0 0}$ \\
\hline
\end{tabular}

* ML Tahmini, birim etkinin standart hatasının tahminidir.

\subsection{Hausman Testi}

F testi ve Score testi modelimizde birim etkilerin olduğu sonucunu vermiştir. $\mathrm{Bu}$ aşamadan sonra birim etkilerin sabit veya tesadüfi olduğunu belirleyen Hausman (1978) testi uygulanmıştır. Hausman testi sabit veya tesadüfi etkiler modelleri arasında karar vermek için, sıfirıncı hipotezin tesadüfi etkiler, alternatif hipotezin ise sabit etkiler olduğu yönünde hipotez türetmektedir (Torres-Reyna, 2007: 29). Testin hipotezi şu şekilde gösterilebilir:

$H_{0}=$ Birim etkisi ile bağımsız değişkenler arasında korelasyon yoktur (Tesadüfi etkiler).

$H_{1}=$ Birim etkisi ile bağımsız değişkenler arasında korelasyon vardır (Sabit etkiler).

Hausman test sonuçları aşağıda Tablo 6'da gösterilmektedir.

Tablo 6. Hausman test sonuçları

\begin{tabular}{|c|c|c|c|}
\hline \multicolumn{4}{|c|}{ Katsayılar } \\
\hline & (b) & (B) & (b-B) \\
\hline & SE & TE & SE-TE \\
\hline $\ln K$ & .2692457 & .2739864 & -.0047407 \\
\hline $\ln \mathrm{L}$ & .6594265 & .7118246 & -.0523981 \\
\hline $\ln T N U M$ & 0870197 & .0949571 & -.0079374 \\
\hline InTREC & .0827751 & .0733218 & .0094533 \\
\hline \multicolumn{4}{|c|}{$\begin{array}{c}\operatorname{chi} 2(4)=8.23 \\
\text { Prob }>\text { chi } 2=0.0835\end{array}$} \\
\hline
\end{tabular}

Hausman test sonucuna göre olasılık değeri \%5 düzeyinde istatistiksel olarak anlamsız bulunmuştur. Dolayısıyla $H_{0}$ hipotezi reddedilememektedir. Bu bağlamda, sabit ve tesadüfi etkiler tahmincisinin tutarlı olduğuna ancak tesadüfi etkiler tahmincisinin etkin olduğu için geçerli olduğuna karar verilmektedir. Analize tesadüfi etkiler modeli ile devam edilmiştir.

\subsection{Tesadüfi Etkiler Modeli Temel Varsayım Testleri}

Tesadüfi etkiler modeli temel varsayımları olan değişen varyans ve otokorelasyon olmamasına yönelik testler Tablo 7'de özetlenmiştir. 
Tablo 7. Tesadüfi Etkiler Modeli temel varsayım testleri

Levene, Brown ve Forsythe Testi
$\mathrm{W} 0=6.955008 \mathrm{df}(6,154) \mathrm{Pr}>\mathrm{F}=0.00000147$
$\mathrm{~W} 50=5.69429 \mathrm{df}(6,154) \mathrm{Pr}>\mathrm{F}=0.00002272$
$\mathrm{~W} 10=6.94335 \mathrm{df}(6,154) \mathrm{Pr}>\mathrm{F}=0.00000151$

Levene, Brown ve Forsythe Testi

$\mathrm{W} 0=6.955008 \mathrm{df}(6,154) \mathrm{Pr}>\mathrm{F}=0.00000147$

$\mathrm{W} 10=6.94335 \mathrm{df}(6,154) \operatorname{Pr}>\mathrm{F}=0.00000151$

\section{Bhargava, Franzini ve \\ Narendranathan'nın Durbin Watson ve \\ Baltagi-Wu Testi}

Durbin-Watson $=0.54630741$

Baltagi-Wu LBI $=0.73806685$

Tablo 7'nin ilk sütununda Levene, Brown ve Forsythe testi sonuçları yer almaktadır. Buna göre Levene, Brown ve Forsythe istatistikleri (W0, W50, W10) $(5,132)$ serbestlik dereceli Snedecor F tablosu ile karşılaştırılarak "birimlerin varyansları eşittir" şeklinde kurulan $H_{0}$ hipotezi reddedilmiştir (Tatoğlu, 2016: 236). Modelde birimlerin varyanslarının eşit olmadığı yani değişen varyans sorunu olduğu anlaşılmaktadır.

Tablo 7'nin ikinci sütununda Bhargava, Franzini ve Narendranathan'nın Durbin Watson ve Baltagi-Wu test sonuçları yer almaktadır. Tablodaki değerlerin ikiye yakın olması birinci mertebe otokorelasyon olmadığını ileri süren sıfır hipotezinin reddedilemeyeceği anlamına gelmektedir. Ancak her iki test sonucu da ikiden küçük olduğu için, $H_{0}$ hipotezi reddedilmektedir $(0.54<2,0.73<2)$. Modelde birinci mertebe otokorelasyon vardır.

\subsection{Arellano, Froot ve Rogers Tahmincisi}

Arellano (1987), Froot (1989) ve Rogers (1993) tesadüfi etkiler tahmincisi ile tahmin edilen bir modelde değişen varyans ve otokorelasyon sorununun birlikte söz konusu olması durumunda dahi dirençli tahminciler elde edilmektedir.

Tablo 8. Arellano, Froot ve Rogers tesadüfi etkiler tahmincisi

\begin{tabular}{lcccc}
\hline \multicolumn{5}{c}{ Tesadüfi Etkiler Tahmincisi } \\
\hline InGDP & Katsayılar & $\begin{array}{c}\text { Robust } \\
\text { Standart Hatalar }\end{array}$ & $\mathbf{z}$ istatistiği & $\mathbf{P}>|\mathbf{z}|$ \\
\hline $\operatorname{lnK}$ & .2739864 & .0155169 & 17.66 & 0.000 \\
$\ln \mathbf{L}$ & .7118246 & .0674301 & 10.56 & 0.000 \\
InTNUM & .0949571 & .021051 & 4.51 & 0.000 \\
lnTREC & .0733218 & .0199093 & 3.68 & 0.000 \\
Sabit & 5.168833 & .9948023 & 5.20 & 0.000 \\
$\boldsymbol{R}^{\mathbf{2}}$ & 0.96 & & & \\
\hline
\end{tabular}

Tablo 8'de yer alan analiz sonuçlarına göre, modelde kullanılan tüm değişkenlerin katsayısı pozitif ve \%1 düzeyinde istatistiki olarak anlamlı bulunmuştur. 7 Akdeniz ülkesinde temel üretim faktörleri olan sermaye ve emek miktarındaki artış literatürle uyumlu olarak ekonomik büyümeyi artırmaktadır. Buna göre, sermayedeki \%1'lik bir artış ekonomik büyümeyi $\% 0,27$ artırırken, emekteki \%1'lik bir artış ekonomik büyümeyi \%0,71 oranında artırmaktadır. Çalışmamızın temel konusu olan turizm geliri ve uluslararası turist sayısının ekonomik büyüme üzerindeki etkisi yine literatürle uyumlu olarak pozitif ve anlamlı sonuç vermiştir. Uluslararası turist sayısındaki \%1'lik bir artış ekonomik büyümeyi \%0,09 oranında artırırken, turizm gelirlerindeki \%1'lik bir artış ekonomik büyümeyi \%0,07 artırmaktadır.

\section{Sonuç ve Öneriler}

Turizm ülkelerin ekonomik, sosyal ve kültürel yapısında değişimler meydana getiren dinamik bir sektördür. Turizm faaliyetlerinin arttı̆̆ bölgelerde yeni çalışma alanları açılarak istihdama katkıda bulunulurken turistlerin yaptığı harcamalarda bu mal ve hizmetleri sağlayanlara gelir olarak dönmektedir. Turizm farklı ülkelerden ve kültürlerden bireyleri bir araya getirme olanağı sağladığından sosyal ve kültürel değerlerin gelişimi açısından toplumlara katkıda bulunmaktadır. 
Turizm Akdeniz'e kıyısı olan ülkeler açısından ekonomik gelişmişlik adına önemli sonuçları olan bir sektördür. Akdeniz ülkeleri dünyada turizm pastasından en çok pay alan ülkeler olarak karşımızda durmaktadır. Bu bağlamda bu ülkelerin ekonomik büyümesinde turizmin etkisinin belirlenmesi uygulanacak politik ve sosyal duruşun bir işareti olabilecektir. Literatürde turizm ve ekonomik büyüme arasındaki ilişkileri inceleyen birçok ampirik çalışma mevcuttur. Bu çalışmaların büyük bir kısmında turizm ve büyüme arasında pozitif bir ilişkinin olduğu tespit edilmiştir.

Bu çalışmada 1995-2017 döneminde 7 Akdeniz ülkesinde turizmin ekonomik büyüme üzerindeki etkisi panel veri analiz yöntemi ile araştırılmıştır. Analiz sonuçlarına göre söz konusu ülkelerde uluslararası turist sayısı ve turizm gelirlerindeki artış ekonomik büyümeyi anlamlı ve pozitif yönde etkilemektedir. Ancak bu etki klasik üretim faktörleri olan emek ve sermayenin yanında düşük kalmaktadır.

Turizm sektörünü sanayi, tarım vb. sektörlerden ayıran en önemli özelliği ekonomik yararlıı̆̆ğı diğer sektörlere nazaran daha kısa sürede gösterebilmesidir. Başarılı bir reklam ve tanıtım kampanyasından kısa bir süre sonra olumlu etkilerini hissettirmektedir. Ancak turizmin bu özelliği ekonomik, siyasal, diplomatik, doğal afet vb. kriz durumlarından da çok çabuk etkilenebileceğini göstermektedir. Dolayısıyla bir ülkenin ekonomik kaynaklarını sadece turizm sektörüne yönlendirmenin hatalı bir davranış olacağı düşünülmektedir. Bu bağlamda turizm sektörü sanayi ve tarım sektörlerini destekleyici bir rol üstlenerek gelişimini sürdürmesi daha faydalı olacaktır.

Bu çalışmada turizm sektörü açısından dünyanın en gelişmiş bölgesinde yer alan Akdeniz ülkeleri verileri kullanılmıştır. Analiz farklı ülke grupları ve turizm verileri ile genişletildiğinde turizmin ekonomik etkileri bağlamında daha kapsamlı sonuçlar elde edileceği düşünülmektedir.

\section{Kaynakça}

Arellano, M. (1987). Practitioners Corner: Computing Robust Standard Errors for Within-groups Estimators, Oxford Bulletin of Economics and Statistics, 49(4): 431-434.

Balaguer, J. and Cantavella-Jordá, M. (2002), Tourism as a long-run economic growth factor: The Spanish case, Applied Economics, 34(7): 877-884.

Bhargava, A., Franzini, L., and Narendranathan, W. (1982), Serial Correlation and the Fixed Effects Model. The Review of Economic Studies, 49(4): 533-549.

Brown, M., B. and Forsythe, A., B. (1974), Robust Tests for the Equality of Variances, Journal of the American Statistical Association, 69(346): 364-367.

Dritsakis, N. (2004). Tourism as A Long-Run Economic Growth Factor: An Empirical Investigation for Greece Using Causality Analysis, Tourism Economics, 10(3): 305-316.

Froot, K., A. (1989). Consistent Covariance Matrix Estimation with Cross-Sectional Dependence and Heteroskedasticity in Financial Data, The Journal of Financial and Quantitative Analysis, 24(3): 333-355.

Gökoval1, U. ve Bahar, O. (2006). Contribution of Tourism to Economic Growth in Mediterrranean Countries: A Panel Data Approach, Anatolia An International Journal of Tourism and Hospitality Research, 17(2): 155-168.

Gunduz, L., and Hatemi-J, A. (2005). Is the Tourism-Led Growth Hypothesis Valid for Turkey? Applied Economics Letters, 12(8): 499-504.

Hausman, J., A., (1978). Specification Tests in Econometrics, Econometrica, 46(6): 1251-1271.

Ongan S, Demiroz D., M. (2005). The Contribution of Tourism to the Long-run Turkish Economic Growth. Ekonomicky Casopis [Journal of Economics], 53: 880-894. 
Proença, S. and Soukiazi, E. (2008). Tourism as an Economic Growth Factor: A Case Study for Southern European Countries, Tourism Economics, 14(4): 791-806.

Rogers, W., H. (1993). Regression Standard Errors in Clustered Samples, Stata Technical Bulletin, (13): 19-23.

Tatoğlu, F., Y., (2016). Panel Veri Ekonometrisi Stata Uygulamal, Beta Yayınevi.

Torres-Reyna, O. (2007). Panel Data Analysis Fixed and Random Effects Using Stata, Data and Statistical Services, Princeton University.

World Tourism Organization (2018). UNWTO Tourism Highlights, 2018 Edition, UNWTO, Madrid. 